Journal of Mathematics and Statistics 7 (3): 184-186, 2011

ISSN 1549-3644

(C) 2011 Science Publications

\title{
Distribution of Records Defined on Ordered Words Representing Lattice Paths
}

\author{
${ }^{1}$ A.M. Alahmadi and ${ }^{2}$ E.A. Mahmoud \\ ${ }^{1}$ Department of Mathematics, Faculty of Science, Taibah University, \\ Almadina Almunwwarah, KSA \\ ${ }^{2}$ Department of Mathematics, Faculty of Science, \\ South Valley University, Aswan, Egypt
}

\begin{abstract}
Problem statement: Let the sequence $i_{1}, i_{2}, \ldots, i_{n}$, denoted by $S_{n}{ }^{n}$ be an increasing ordered word of length $n$ taken from the set of the $n$ positive integers $S=\{1,2, \ldots, n\}, m, n \in N^{+}, m \geq n$.. Approach: That is $1 \leq \mathrm{i}_{1} \leq \mathrm{i}_{2} \leq \ldots \leq \mathrm{i}_{\mathrm{n}} \leq \mathrm{n}$. Treating $\mathrm{S}_{\mathrm{n}}{ }^{\mathrm{n}}$ as a sequence of weak records $\left\{\mathrm{L}_{\mathrm{j}}=\mathrm{i}_{\mathrm{j}}\right\}, \mathrm{i}, \mathrm{j}=$ $1,2, \ldots, \mathrm{n}$, the distribution of the single weak record as well as the joint distribution of weak records were found before. Results: By defining the notion of strong records on the sequence $\left\{\mathrm{L}_{\mathrm{j}}=\mathrm{i}_{\mathrm{j}}\right\}$, the distribution of a single strong record was found for $m=n$. In another aspect, it can be shown that the lattice path in the plane from $(0,1)$ to $(\mathrm{m}, \mathrm{n})$, consisting of unit segments up and to the right, can be represented by a sequence $i_{1}, i_{2}, \ldots, i_{m}$ where $1 \leq i_{1} \leq i_{2} \leq \ldots \leq i_{m} \leq n, m, n \in N^{+} m \geq n$. That is, such lattice paths can be represented, in one to one correspondence, by ordered increasing words of length $\mathrm{m}$ taken from the set S. Conclusion/Recommendations: In this article, we are going to extend the notion of weak and strong records to these sequences representing lattice paths for $m>n$ and obtain their distributions. This result allows us to study lattice paths via ordered words of non negative integers.
\end{abstract}

Key words: Lattice paths, increasing ordered words, random variables, probability distribution

\section{INTRODUCTION}

An ordered word of length $\mathrm{m}$ taken from the set $\mathrm{S}$ $=\{1,2, \ldots, n\}$ Alahmadi (2009), is a set of $m$ integers $i_{1}$, $\mathrm{i}_{2}, \ldots, \mathrm{i}_{\mathrm{m}}$ such that $1 \leq \mathrm{i}_{1} \leq \mathrm{i}_{2} \leq \ldots \leq \mathrm{i}_{\mathrm{m}} \leq \mathrm{n}, \mathrm{m}, \mathrm{n} \in \mathrm{N}^{+}$. For $\mathrm{n}=\mathrm{m}$, the element $\mathrm{i}_{\mathrm{j}}, \mathrm{i}, \mathrm{j}=1,2, \ldots, n$. is denoted by the weak record $L_{i}$ the probability distribution of a single $L_{j}$ as well as the joint probability distribution of $\mathrm{L}_{\mathrm{i}}, \mathrm{L}_{\mathrm{i}_{2}}, \ldots, \mathrm{L}_{\mathrm{i}_{\mathrm{k}}}$, where $1 \leq \mathrm{i}_{1} \leq \mathrm{i}_{2} \leq \ldots \leq \mathrm{i}_{\mathrm{k}} \leq \mathrm{n}$, were given by the following theorem, for other results on ordered sequences El-Faheem and Mahmoud (2010), Khidr and Radwan (2000).

Theorem 1: Let $P\left(L_{i}=j\right)$ be the probability that the integer $\mathrm{j}$ falls in the $\mathrm{i}^{\text {th }}$ place in the sequence $\mathrm{j}_{1} \mathrm{j}_{2} \ldots \mathrm{j}_{\mathrm{n}}, \mathrm{l}_{\mathrm{i}}=$ $1,2, \ldots$, n. then we have Eqn. 1:

$P\left(L_{i}=j\right)=\left(\begin{array}{c}i+j-2 \\ j-1\end{array}\right)\left(\begin{array}{c}2 n-i-j \\ n-j\end{array}\right), j=1,2, \ldots, n$

Similarly, if $P\left(\left(\mathrm{~L}_{\mathrm{i}_{1}}=\mathrm{j}_{\mathrm{i}}, \mathrm{L}_{\mathrm{i}_{2}}=\mathrm{j}_{\mathrm{i}} . ., \mathrm{L}_{\mathrm{i}_{1}} \mathrm{j}_{\mathrm{k}}\right)\right.$ be the the probability that the numbers $\mathrm{j}_{1}, \mathrm{j}_{1}, \ldots, \mathrm{j}_{\mathrm{k}}$ falling in the locations $i_{1}, i_{2}, \ldots, i_{k}$, respectively, then Eq. 2 :

$$
\begin{aligned}
& P\left(L_{i_{1}}=j_{1}, L_{i_{2}}=j_{2}, \ldots, L_{i_{k}}=j_{k}\right)= \\
& \left(\begin{array}{c}
i_{1}+j_{1}-2 \\
j_{1}-1
\end{array}\right)\left(\begin{array}{c}
i_{2}+j_{2}-i_{1}-j_{1}-1 \\
j_{2}-j_{1}-1
\end{array}\right) \ldots\left(\begin{array}{c}
i_{k}+j_{k}-i_{k-1}-j_{k-1}-1 \\
j_{k}-j_{k-1}=1
\end{array}\right)\left(\begin{array}{c}
2 n-i_{k}-j_{k} \\
n-j_{k}
\end{array}\right)
\end{aligned}
$$

In the case $m>n$, similar expressios are given for $\mathrm{P}\left(\left(\mathrm{L}_{\mathrm{i}_{1}}=\mathrm{j}_{1}, \mathrm{~L}_{\mathrm{i}_{2}}=\mathrm{j}_{2}, \ldots \ldots, \mathrm{L}_{\mathrm{i}_{\mathrm{k}}}=\mathrm{j}_{\mathrm{k}}\right) \leq \mathrm{j} \leq \mathrm{j}_{2} \leq \ldots \leq \mathrm{j}_{\mathrm{k}} \leq \mathrm{n}, \leq \mathrm{k} \leq \mathrm{m}\right.$.

We notice that $1 \leq \mathrm{L}_{\mathrm{i}_{1}} \leq \mathrm{L}_{\mathrm{i}_{2}} \leq \ldots \leq \mathrm{L}_{\mathrm{i}_{\mathrm{k}}} \leq \mathrm{n}$, thus they form some kind of weak records, the strong record on the sequence $\mathrm{j}_{1} \mathrm{j}_{2} \ldots \mathrm{j}_{\mathrm{n}}$ or alternately on $\mathrm{L}_{\mathrm{i}_{1}}, \mathrm{~L}_{\mathrm{i}_{2}}, \ldots, \mathrm{L}_{\mathrm{i}_{\mathrm{k}}}$ was introduced as a parallel to record values in the continuous case. For records from continuous distributions, Ahsanullah and Ragab (2006) Ahsanullah (1995) for discrete records, Dembinska (2007).

\section{MATERIALS AND METHODS}

\section{Definition 1: For $m \geq n$.}

Let $\mathrm{R}(1)=1$ and $\mathrm{R}(\mathrm{i}+1)=\min \left\{\mathrm{k}>\mathrm{R}(\mathrm{i}): \mathrm{L}_{\mathrm{k}}>\mathrm{X}_{\mathrm{R}(\mathrm{i})}\right.$ when $\mathrm{L}_{\mathrm{k}}$ exists, otherwise $\mathrm{R}(\mathrm{i}+\mathrm{t})=\mathrm{R}(\mathrm{i}), \mathrm{t}=1,2, \ldots, \mathrm{m}-\mathrm{i}$ \}, then $\mathrm{X}_{\mathrm{R}(1)}, \mathrm{X}_{\mathrm{R}(2)}, \ldots, \mathrm{X}_{\mathrm{R}(\mathrm{m})}$ are called the strong record values on $L_{1}, L_{2}, \ldots, L_{m}$. and $P\left(X_{R(1)}=k\right)$ is given by the following theorem Eqn. 3. 
Theorem 2:

$$
\begin{aligned}
& P\left(X_{R(i)}=k\right)=\left(\begin{array}{c}
k-1 \\
i-1
\end{array}\right)\left(\begin{array}{c}
2 n-k-1 \\
n-i
\end{array}\right)+ \\
& \sum_{r=0}^{i-2}\left(\begin{array}{c}
n-1 \\
r
\end{array}\right)\left(\begin{array}{c}
k-1 \\
r
\end{array}\right) i=1,2, \ldots, n ; k=1,2, \ldots, n
\end{aligned}
$$

In this article, we generalize Theorem 2 for $m>n$. to get.

Theorem 3: For $m>n$, the distribution of the record value $\mathrm{X}_{\mathrm{R}(\mathrm{i})=\mathrm{k}}$ is equal to Eqn. 4 :

$$
\begin{aligned}
& P\left(X_{R(i)}=k\right)=\left(\begin{array}{c}
k-1 \\
i-1
\end{array}\right)\left(\begin{array}{c}
m+n-k-1 \\
m-i
\end{array}\right)+ \\
& \sum_{r=0}^{i-2}\left(\begin{array}{c}
m-1 \\
r
\end{array}\right)\left(\begin{array}{c}
k-1 \\
r
\end{array}\right) i=1,2, \ldots, m ; k=1,2, \ldots, n
\end{aligned}
$$

The case $m<n$, can be obtained from (3) by interchanging $\mathrm{m}$ and $\mathrm{n}$ in (2).

Proof of theorem 3: We call the sequence of random variables $\mathrm{L}_{1} \mathrm{~L}_{2} \ldots \mathrm{L}_{\mathrm{m}}$ (alternatively the ordered word $\left.\mathrm{j}_{1} \mathrm{j}_{2} \ldots \mathrm{j}_{\mathrm{m}}\right)$ the original sequence and its corresponding sequence of the record values, $X_{R(1)} X_{R(2)} \ldots X_{R(m)}$, the reduced sequences. For example, for $\mathrm{n}=6, \mathrm{~m}=7$, the sequence of random variables 2234666 is an original sequence and its corresponding records 2346666 is the corresponding reduced sequence. We notice that the value of the $i^{\text {st }}$ record $X_{R(i)}$ is equal to the $i^{\text {st }}$ entry in the reduced sequence, $\mathrm{I}=1,2, \ldots, \mathrm{m}$ Therefore, to obtain the number of original sequences $L_{1} \quad L_{2} L_{3} \ldots L_{m}$, or alternatively $\mathrm{j}_{1} \mathrm{j}_{2} \ldots \mathrm{j}_{\mathrm{m}}$, contributing to the event $\mathrm{X}_{\mathrm{R}(\mathrm{i})}=\mathrm{k}$, $\mathrm{i}>1$ ( for $\mathrm{i}=1$, by definition $1, \mathrm{P}\left(\mathrm{X}_{\mathrm{R}(1)}=\mathrm{k}\right)=\mathrm{P}\left(\mathrm{L}_{1}=\mathrm{k}\right.$ ), we have to look for the reduced sequences which have the $\mathrm{i}^{\text {st }}$ entry equal to $\mathrm{k}, \mathrm{k}=1,2, . ., \mathrm{n}$. These reduced sequences are one of two types.

Type 1, sequences which have the first $r$ entries $\mathrm{X}_{\mathrm{R}(1)} \cdot \mathrm{X}_{\mathrm{R}(2)} \ldots \mathrm{X}_{\mathrm{R}(\mathrm{r})}$ form an strictly increasing ordered word from the set $\{1,2, \ldots,(\mathrm{k}-1)\}, 0 \leq \mathrm{r} \leq(\mathrm{i}-2), \mathrm{i}>1$. The remaining elements of the sequence are all equal to $\mathrm{k}$. These sequences will be of the form:

$$
\begin{aligned}
& \mathrm{X}_{\mathrm{R}(1)} \mathrm{X}_{\mathrm{R}(2)} \ldots \mathrm{X}_{\mathrm{R}(\mathrm{r})} \mathrm{X}_{\mathrm{R}(\mathrm{r}+1)} \mathrm{X}_{\mathrm{R}(\mathrm{r}+2)} \ldots \mathrm{X}_{\mathrm{R}(\mathrm{m})}= \\
& \mathrm{j}_{1} \mathrm{j}_{2} \ldots \mathrm{j}_{\mathrm{r}} \mathrm{j}_{(\mathrm{r}+1)} \mathrm{j}_{(\mathrm{r}+2)} \ldots \mathrm{j}_{\mathrm{m}}
\end{aligned}
$$

With:

$$
\begin{aligned}
& 1 \leq \mathrm{j}_{1}<\mathrm{j}_{2}<\ldots<\mathrm{j}_{\mathrm{r}} \leq(\mathrm{k}-1), \mathrm{j}_{\mathrm{s}}=\mathrm{k}, \\
& \mathrm{s}=(\mathrm{r}+1),(\mathrm{r}+2), \ldots, \mathrm{m}
\end{aligned}
$$

Or what is the same:

$$
\begin{aligned}
& \mathrm{X}_{\mathrm{R}(1)} \mathrm{X}_{\mathrm{R}(2)} \ldots \mathrm{X}_{\mathrm{R}(\mathrm{r})} \mathrm{X}_{\mathrm{R}(\mathrm{r}+1)} \mathrm{X}_{\mathrm{R}(\mathrm{r}+2)} \ldots \mathrm{X}_{\mathrm{R}(\mathrm{m})}= \\
& \mathrm{j}_{1} \mathrm{j}_{2} \ldots \mathrm{j}_{\mathrm{r}} \mathrm{kk} \ldots \mathrm{k}
\end{aligned}
$$

$$
\text { When } r=0,(5) \text {, reduces to the sequence kkk...k }
$$

Type 2, sequences with the first (i-1) entries are formed of strictly increasing words from the set $\{1,2, \ldots,(\mathrm{k}-1)\}$, the $\mathrm{i}^{\text {st }}$ entry equals $\mathrm{k}$ and the remaining $(\mathrm{m}-\mathrm{i})$ entries are formed of strictly increasing ordered word formed from the set $\{k,(k+1), \ldots, n$.$\} . These$ sequences are of the form Eqn. 6:

$$
\begin{aligned}
& \mathrm{X}_{\mathrm{R}(1)} \mathrm{X}_{\mathrm{R}(2)} \ldots \mathrm{X}_{\mathrm{R}(\mathrm{i}-1)} \mathrm{X}_{\mathrm{R}(\mathrm{i})} \mathrm{X}_{\mathrm{R}(\mathrm{i}+1)} \ldots \mathrm{X}_{\mathrm{R}(\mathrm{m})}= \\
& \mathrm{j}_{1} \mathrm{j}_{2} \ldots \mathrm{j}_{(\mathrm{i}-1)} \mathrm{kj}_{(\mathrm{i}+1)} \ldots \mathrm{j}_{\mathrm{m}} \text { with } \\
& 1 \leq \mathrm{j}_{1}<\mathrm{j}_{2}<\ldots<\mathrm{j}_{(\mathrm{i}-1)} \leq(\mathrm{k}-1), \mathrm{j}_{\mathrm{i}}=\mathrm{k} \\
& \mathrm{k} \leq \mathrm{j}_{(\mathrm{i}+1)} \leq \ldots \leq \mathrm{j}_{\mathrm{m}} \leq \mathrm{n}
\end{aligned}
$$

After determining the reduced sequences that contribute to the event $\mathrm{X}_{\mathrm{R}(\mathrm{i})}=\mathrm{k}, \mathrm{i}>1, \mathrm{k}=1,2, \ldots, \mathrm{n}$. as in (1-2), we have to look for the original sequences that give these reduced sequences when applying definition 3.

For the reduced sequences in (2.1), we can construct the original sequences that give them as follows: From the set of integers $\{1,2, \ldots,(\mathrm{k}-1)\}$, we select $r$ integers without replacement in $\left(\begin{array}{c}\mathrm{k}-1 \\ \mathrm{r}\end{array}\right)$ ways, denote these $r$ integers $j_{1}, j_{2}, \ldots j_{r}, 0 \leq r \leq(i-1)$. From the $m$ places reserved for the sequence $L_{1} L_{2} L_{3} \ldots L_{m}$, we save the last location for the integer $\mathrm{k}$ and choose from the remaining ( $n-1)$ places, $r$ places for the previously selected $r$ integers in $\left(\begin{array}{c}m-1 \\ r\end{array}\right)$ ways. Place these $r$ integers in the $r$ selected places to get the following arrangement bellow:

$$
\begin{array}{llll}
\mathrm{j}_{\mathrm{i}} & \mathrm{j}_{2} & \mathrm{j}_{\mathrm{r}} & \mathrm{k}
\end{array}
$$

Now we fill in the empty places by the integer succeeding it to get the following arrangement:

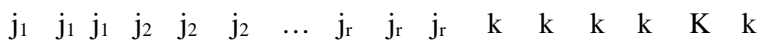

Clearly, the above arrangement, as original sequence, gives a reduced sequence as in (1). The number of such original sequences, for particular $r$ is $\left(\begin{array}{c}n-1 \\ r\end{array}\right)\left(\begin{array}{c}k-1 \\ r\end{array}\right)$, Summing over $r=0,2, \ldots,(i-2)$, we see that the number of original sequences that give reduced sequences as in (7) is equal to: 
$\sum_{r=0}^{\mathrm{i}-2}\left(\begin{array}{c}\mathrm{m}-1 \\ \mathrm{r}\end{array}\right)\left(\begin{array}{c}\mathrm{k}-1 \\ \mathrm{r}\end{array}\right)$

For the reduced sequences in (8), we can see that the original sequences that can give the reduced sequences of type 2, as in (8), are of the form as below:

$\begin{array}{llllllllllllllll}\mathrm{j}_{1} & \ldots & \mathrm{j}_{1} & \mathrm{j}_{2} & \ldots & \mathrm{j}_{2} & \ldots & \mathrm{j}_{(\mathrm{i}-1)} & \ldots & \mathrm{j}_{(\mathrm{i}-1)} & \mathrm{k} & \mathrm{j}_{(\mathrm{i}+1)} & \ldots & \mathrm{j}_{\mathrm{m}}\end{array}$

Where:

$$
\begin{aligned}
& 1 \leq \mathrm{j}_{1}<\mathrm{j}_{2}<\ldots<\mathrm{j}_{(\mathrm{i}-1)} \leq(\mathrm{k}-1), \mathrm{j}_{\mathrm{i}}=\mathrm{k}, \\
& \mathrm{k} \leq \mathrm{j}_{(\mathrm{i}+1)} \leq \ldots \leq \mathrm{j}_{\mathrm{m}} \leq \mathrm{n}
\end{aligned}
$$

The number of the arrangements (2.4) can be obtained as follows: chose (i-1) strictly increasing positive integers, $1 \leq \mathrm{j}_{1}<\mathrm{j}_{2}<\ldots<\mathrm{j}_{(\mathrm{i}-1)} \leq(\mathrm{k}-1)$, out the set $\{1,2, . ., \mathrm{k}\}$ in $\left(\begin{array}{c}\mathrm{k}-1 \\ \mathrm{i}-1\end{array}\right)$ ways. Then we take the first s places $\mathrm{I} \leq \mathrm{s} \leq \mathrm{m}$, we save the $\mathrm{s}^{\text {st }}$ place for the integer $\mathrm{k}$ and choose from the remaining (s-1) places, (i-1) places for the (i-1) integers, $1 \leq \mathrm{j}_{1}<\mathrm{j}_{2}<\ldots<\mathrm{j}_{(\mathrm{i}-1)} \leq(\mathrm{k}-1)$ and fill in the empty ( $\mathrm{s}-\mathrm{i}$ ) places , as before, by the integers succeeding each. This gives us the first part of the scheme (9). To obtain the arrangement (9), we fill in the remaining (m$\mathrm{s})$ places by ordered words of length (m-s) formed from the set $\{\mathrm{k}, \mathrm{k}+1, \ldots, \mathrm{n}\}$.

The total number of original sequences of type 2 will be equal to:

$$
\left(\begin{array}{c}
k-1 \\
i-1
\end{array}\right) \sum_{s=i}^{m}\left(\begin{array}{c}
s-1 \\
i-1
\end{array}\right)\left(\begin{array}{c}
m-s+n-k-1 \\
m-s
\end{array}\right)
$$

The sum in (10) is equal to:

$$
\left(\begin{array}{c}
\mathrm{m}+\mathrm{n}-\mathrm{k}-1 \\
\mathrm{~m}-\mathrm{i}
\end{array}\right)
$$

thus (5) equals to:

$$
\left(\begin{array}{c}
k-1 \\
i-1
\end{array}\right)\left(\begin{array}{c}
m+n-k-1 \\
m-i
\end{array}\right)
$$

From (3) and (6), the theorem follows.

\section{RESULTS}

Theorem 2 is an extension to theorem 1 and the following Table 1 can be used to justify the theorem.

\begin{tabular}{lrrrrl} 
Table $1:\left(\begin{array}{c}\mathrm{m}+\mathrm{n}-1 \\
\mathrm{~m}\end{array}\right) \mathrm{P}\left(\mathrm{X}_{\mathrm{R}(\mathrm{i})}=\mathrm{k}\right)$ & & & \\
\hline $\mathrm{k} / \mathrm{I}$ & 1 & 2 & 3 & 4 & 5 \\
\hline 1 & 210 & 84 & 28 & 7 & 1 \\
2 & 1 & 127 & 113 & 64 & 25 \\
3 & 1 & 7 & 83 & 124 & 115 \\
4 & 1 & 7 & 28 & 99 & 195 \\
5 & 1 & 7 & 28 & 84 & 210 \\
6 & 1 & 7 & 28 & 84 & 210 \\
7 & 1 & 7 & 28 & 84 & 210 \\
\hline
\end{tabular}

\section{DISCUSSION}

It is interesting to proof a similar theorem to theorem 1 and 2 , in case the sequence $1 \leq \mathrm{i}_{1} \leq \mathrm{i}_{2} \leq \ldots \leq \mathrm{i}_{\mathrm{k}} \leq \mathrm{n}$ represents the order statistics from the discrete uniform distribution on $\mathrm{S}=\{1,2, \ldots, \mathrm{n}\}$. The result if obtained, can be used together with current result in testing hypotheses concerning records.

\section{CONCLUSION}

The study of lattice paths is closely related to the study of increasing ordered words of non negative integers, this relation can facilitate the study of either via the other.

\section{REFERENCES}

Ahsanullah, M. and M.Z. Ragab, 2006. Bounds and Characterizations of Record Statistics. 1st Edn., Nova Science Pub, Inc., New York, ISBN: 10: 1594545383, pp: 177.

Ahsanullah, M., 1995. Record Statistics. 1st Edn., Nova Science. Publishers, Inc., New York, ISBN10:1560722037, pp: 224.

Alahmadi, A. M., 2009. Extension of a matching problem. JTUSCI, 2: 88-93.

Dembinska, A., 2007. A review on characterizations of discrete distributions based on records and kth records. Commun. Stat. Theory Methods, 36: 1381-1387. DOI: 10.1080/03610920601077113

El-Faheem, A.A. and E.A. Mahmoud, 2010. The probability and asymptotic distribution functions of ordered statistical data. J. Math. Stat., 6: 217-220, 2010. DOI: 10.3844/jmssp.2010.217.220

Khidr, A.M. and A.A. Radwan, 2000. Artificial order statistics. J. Ind. Stat. Soc. Operat. Res., 16: 1-5. 